\title{
TRIBUTACIÓN AL CONSUMO DE ESPECTÁCULOS CINEMATOGRÁFICOS Y ASISTENCIA DEL CONSUMIDOR AL CINE POR FILMES PERUANOS
}

\author{
TAXATION TO THE CONSUMPTION OF MOTION PICTURES AND CONSUMER \\ ATTENDANCE TO CINEMA BY PERUVIAN FILMS
}

José Luis CoRnejo ViLCARINO Universidad Nacional Mayor de San Marcos Lima, Perú

ORCID: https://orcid.org/0000-0002-1095-0005

Correo electrónico: jose.cornejo1@unmsm.edu.pe

\section{RESUMEN}

Objetivo: Determinar la relación entre la tributación al consumo de espectáculos cinematográficos y la asistencia del consumidor al cine por filmes peruanos en el periodo 2017-2019. Método: La investigación fue de tipo cuantitativo, correlacional, transversal y descriptivo. El diseño fue no experimental. La muestra estuvo compuesta por 384 consumidores de entre los 15 a 53 años que asistieron a Cineplanet sede Centro Cívico de Lima durante el periodo 2017-2019. Resultados: Existe una correlación significativa inversa baja, con coeficiente de $r=-0,238$, entre la tributación al consumo de espectáculos cinematográficos y la asistencia del consumidor al cine por filmes peruanos, pues aun cuando se plantee el escenario de que no exista la tributación al consumo para los espectáculos cinematográficos nacionales, el $5,73 \%$ de los encuestados indica que la asistencia del consumidor sería baja; el $17,71 \%$, regular; el $47,14 \%$, alta; y el $5,73 \%$, muy alta, mientras que para el $23,69 \%$ no existe correlación de las variables. Conclusión: Aún sin correlación inversa perfecta de variables, la tributación al consumo de los espectáculos cinematográficos es uno de los componentes que influye al momento de que el consumidor decida asistir al cine por filmes peruanos.

Palabras clave: Tributación al consumo; impuesto general a las ventas; impuesto de promoción municipal; impuesto a los espectáculos públicos no deportivos; cine peruano.

\begin{abstract}
Objective: Determine the relationship between consumption taxation of motion pictures and consumer attendance to the cinema for Peruvian films in the period 2017-2019. Method: The investigation was quantitative, correlational, cross-sectional and descriptive. The design was non-experimental. The sample was comprised of 384 consumers between the ages of 15 to 53 years old who attended Cineplanet's Civic Center of Lima location during the period of 20172019. Results: There is a low inverse significant correlation, with a coefficient of $r=-0,238$, between consumption taxation of motion pictures and consumer attendance to the cinema for Peruvian films, because even if the scenario of no consumption taxation for national motion pictures is posed, $5,73 \%$ of the respondents indicate that consumer attendance would be low; $17,71 \%$, regular; $47,14 \%$ high; and $5,73 \%$, very high, while for $23,69 \%$ there is no correlation between the variables. Conclusion: Even without perfect inverse correlation of variables, the consumption taxation of motion pictures is one of the components that influence the consumer's decision whether go to the movies for Peruvian films or not.
\end{abstract}

Keywords: Tonsumption tax; general sales tax; municipal promotion tax; tax on non-sports public shows; Peruvian cinema. 


\section{INTRODUCCIÓN}

Los espectáculos cinematográficos son una de las actividades económicas más consumidas dentro del ámbito del entretenimiento, las cuales trasmiten contenidos de gran variedad y para cada tipo de consumidor. Como actividad económica, el consumo de dichos espectáculos genera el crecimiento empresarial tanto de las empresas productoras como distribuidoras de películas, lo cual a su vez genera puestos de trabajo.

El crecimiento de este sector a nivel nacional lleva a una mayor recaudación tributaria para el fisco, ya sea por los beneficios empresariales sobre los cuales se aplica el impuesto a la renta, así como las rentas de trabajo a las que también recae el referido impuesto, además de los tributos al consumo de dichos espectáculos.

La asistencia de los consumidores a los cines por filmes peruanos a nivel nacional en los años 2017, 2018 y 2019 solo representó el 9,74\%, 12,23\% y 4,84\%, respectivamente, mientras que la cantidad de películas peruanas estrenadas en los referidos años respecto del total general de películas estrenadas en todo el Perú solo reflejó un 8,33\%, $7,98 \%$ y 10,76\%, respectivamente (Dirección del Audiovisual, la Fonografía y los Nuevos Medios, 2020). Así también, estudios señalan que solo un $5 \%$ de los consumidores de los espectáculos cinematográficos prefieren las películas de producción nacional (Gestión, 2020). Siendo ello así, es evidente la preferencia de los consumidores por las películas extranjeras sobre las películas peruanas.

La poca preferencia de los referidos consumidores por las producciones nacionales no es un problema reciente. A través de los años, el Estado ha venido implementando normas que incorporan incentivos tributarios tanto a la producción como exhibición de películas peruanas. Como prueba de esto, se tiene que en el año 1962, en el Congreso de la República, se aprobó la ley denominada "Liberando de toda clase de impuestos y arbitrios, la exhibición de las películas nacionales, de largo metraje, producidas en el país por empresas nacionales" (Ley № 13936, 1962) y para el año 1972, desde el Ejecutivo, se promulgó la Ley de Fomento de la Industria Cinematográfica (Decreto Ley $\mathrm{N}^{\circ} 19327,1972$ ).

Por otra parte, en el año 1994, se aprobó la Ley № 26370, denominada Ley de la Cinematografía Peruana, la cual dejó sin efecto muchos de los incentivos tributarios con que gozaban las compañías productoras y exhibidoras de películas de origen nacional (Ley $\mathrm{N}^{\circ} 26370,1994$ ). Asimismo, el 8 de diciembre de 2019, se publicó en el Diario Oficial el "Decreto de Urgencia que promueve la actividad cinematográfica y audiovisual” (Decreto de Urgencia $\mathrm{N}^{\circ}$ 022-2019, 2019), actualmente vigente, cuyo fin es incentivar esta actividad tanto a nivel gráfico como audiovisual con el propósito de buscar un desarrollo general, progresivo y con una visión inclusiva. Dicha norma concede beneficios económicos para esta actividad en tanto sea nacional y, a la vez, implementa beneficios frente al fisco a las compañías que realicen donaciones en favor de la producción de esta actividad.

En ese sentido, si bien el Estado ha venido incorporando incentivos tributarios para producir, distribuir, así como exhibir filmes nacionales, a la fecha no existe ningún incentivo tributario para el consumidor de espectáculos cinematográficos; es decir, estos pagan el mismo precio por entradas al cine por películas tanto nacionales como extranjeras, aun teniendo en cuenta que el factor consumo es necesario para que una actividad económica conlleve a generar ingresos para los productores, distribuidores y exhibidores de películas.

Cabe señalar que "los peruanos son considerados los más cinéfilos de la región al consignarse que el 49\% de ellos realiza una visita al cine por lo menos una vez a la semana" (El Comercio, 2019, párr. 1), por lo que podría considerarse como posibilidad una inafectación o exoneración de tributos al consumo a las entradas a las salas de cine por películas peruanas para, de esa forma, incentivar su consumo; más aún, teniendo en cuenta, según Huanqui (2017), el creciente y gradual reconocimiento de la calidad de las películas peruanas de los últimos años.

Efectivamente, hay películas peruanas que cumplen el estándar internacional, es decir, que han sido reconocidas internacionalmente por su buena calidad cinematográfica. Ejemplo, entre otros, es la película peruana Retablo estrenada en el 2019, la cual cuenta con cerca de " 50 premios internacionales ganados en múltiples festivales extranjeros como en La Habana, Toronto, San Francisco, Nueva York, Sydney, Chicago, Ginebra, Sudáfrica, Vancouver, Bilbao, Bucharest, Brasil, China” (RPP Noticias, 2020, párr. 5).

A la fecha, los espectáculos cinematográficos tanto de películas peruanas como extranjeras están gravadas para el consumidor con una tasa del $16 \%$ y $2 \%$ de impuesto general a las ventas (IGV) y de impuesto de promoción municipal (IPM), respectivamente, que son recaudados por el Gobierno central así como, adicionalmente, con una tasa del 10\% de impuesto a los espectáculos públicos no deportivos (IEPND) que son recaudados por las municipalidades distritales. Dichos tributos llevan a que un boleto de entrada al cine que tuviese como valor de venta $S / 13,90$ tenga, con la afectación a los tributos al consumo indicados, un precio de venta final de S/ 18,00.

En consecuencia, es necesario determinar la relación que existe entre los tributos al consumo que paga el consumidor 
por estos espectáculos cinematográficos y el nivel de asistencia por el consumo de filmes peruanos en los cines, y así señalar que sería un incentivo tributario a la producción y exhibición de películas peruanas el no gravar con el IGV, IPM ni IEPND al consumo de estos, siendo un servicio sustituto frente a las películas extranjeras, en caso el consumidor considere el factor precio como necesario para elegir entre una película peruana o extranjera.

Por ello, se tiene la siguiente pregunta general de investigación: ¿Existe relación entre la tributación al consumo de espectáculos cinematográficos y la asistencia del consumidor al cine por filmes peruanos 2017-2019? Así como dos preguntas específicas, las cuales son: ¿Existe relación entre el IGV e IPM al consumo de espectáculos cinematográficos y la asistencia del consumidor al cine por filmes peruanos en el periodo 2017-2019? y ¿ existe relación entre el IEPND al consumo de espectáculos cinematográficos y la asistencia del consumidor al cine por filmes peruanos en el periodo 2017-2019? La hipótesis general es que existe una relación significativamente inversa entre la tributación al consumo de espectáculos cinematográficos y la asistencia del consumidor al cine por filmes peruanos (2017-2019). Las hipótesis específicas que se plantean indican que existe una relación significativamente inversa entre el IGV, IPM e IEPND al consumo de espectáculos cinematográficos y la asistencia del consumidor al cine por filmes peruanos (2017-2019).

No ha sido posible encontrar antecedentes recientes directamente relacionados con la investigación, no obstante, se han revisado antecedentes vinculados con las variables. Sobre la efectividad de las exoneraciones al IGV, Alfaro (2017) concluye, según su estudio al año 2015, que la exoneración al IGV tiene una respuesta beneficiosa para las empresas del sector construcción de la región San Martín, pues este beneficio tributario promueve su desarrollo sea esta privada o pública. Si bien dicha investigación hace referencia sobre otra actividad económica, se puede observar que es posible, en algunos sectores, aplicar la exoneración del IGV, juntamente con el IPM, para promover una actividad.

Por otra parte, en referencia a los costos tributarios que implicaría una inafectación al IEPND para una municipalidad distrital, Chang (2020) concluye en su trabajo de investigación que, así como la Municipalidad Distrital de Cayma, las demás municipalidades ubicadas en el Perú tienen diversos tributos municipales vinculados con trámites, eventos y espectáculos que no dan un soporte financiero sólido a cada una de las municipalidades para que puedan prestar los servicios necesarios a sus comunidades. Además, menciona que los tributos municipales como el IEPND no generan grandes ingresos a un Gobierno local, caso distinto del impuesto predial o de alcabala, o de las transferencias económicas del Gobierno central a través del Fondo de Compensación Municipal (FONCOMUN).

En España, con relación al consumo de espectáculos cinematográficos y la importancia del componente precio, Gil (2015) determina que el precio tiene una importante influencia al momento de asistir a los cines, pues según el $90 \%$ de sus encuestados es el precio el que interviene mucho a la hora de decidir ir al cine; así como un 57\% manifiesta que el espectáculo cinematográfico no supera el precio pagado, por lo que el precio sería un componente discriminador a la hora de acudir a este espectáculo. Si bien esto también depende de la capacidad de gasto en cuanto a servicios de entretenimiento, en el universo de consumidores, el precio de la entrada al cine podría influir al momento de decidir ver una película o no; siendo los tributos al consumo sobre estos servicios los que aumenten el precio de venta.

Como ya se hizo mención, los tributos al consumo que gravan a los espectáculos cinematográficos son el IGV, IPM y el IEPND. En cuanto al IGV, teniendo en cuenta el Texto Único Ordenado de la Ley de Impuesto General a las Ventas e Impuesto Selectivo al Consumo (Decreto Supremo No 055-99-EF, 1999), se puede señalar que es aquel que grava cada fase del ciclo productivo y distributivo de forma no acumulativa; es decir, grava solo el valor que es agregado en cada fase y es asumido por el consumidor en la fase final, pues se incluye en el precio de venta al momento de adquirir un bien o servicio, mecanismo que se lleva a cabo a través del débito contra el crédito en el IGV aplicado por cada fase mediante la sustracción, a efectos de solo calcular el IGV como deuda tributaria a pagar.

En cuanto al IPM, es un impuesto con tasa del 2\% que tiene el mismo mecanismo de aplicación que el IGV, pues se rige por sus mismas normas (Decreto Supremo No 156 2004-EF, 2004), por lo que en general, se considera al IGV junto con el referido impuesto como una única tasa del $18 \%$, aunque técnicamente es incorrecto. Su diferenciación con el IGV es netamente de destino recaudatorio, pues el IPM no será un ingreso del Gobierno central como el IGV; sino que, aun siendo un tributo nacional y no municipal, se destinará como ingreso para cada uno de los municipios del Perú, sea provincial o distrital, a través del FONCOMUN.

El IEPND es definido como un impuesto que "grava el monto que se abona por presenciar o participar en espectáculos públicos no deportivos que se realicen en locales o parques cerrados" (Decreto Supremo No 156-2004-EF, 2004, art. 54 ), por lo que la obligación de tributar nace al momento en que se paga el derecho de ingreso, ya sea para participar o presenciar el espectáculo. Por su parte, según Ruiz de Castilla (2008), si bien los impuestos pueden gravar tanto 
la renta, el consumo e incluso el patrimonio, el IEPND grava al consumo vinculado con servicios de recreación y/o diversión que suponen una buena capacidad tributaria del consumidor de dichos servicios.

En cuanto al consumo de espectáculos cinematográficos y la asistencia al cine por filmes peruanos, es necesario precisar que todo negocio se mantiene y crece a través del consumo. Es así como un bien o servicio certificado y recomendado a nivel nacional o internacional por las entidades especializadas en la materia no podrá generar ganancias al empresario que lo produzca, en tanto el consumo no sea masivo en los consumidores. Por ello, existen políticas de Estado que buscan incentivar el consumo de la producción nacional, sea esta por subsidios económicos, exoneraciones o inafectaciones tributarias, restricciones o limitaciones al consumo de bienes o servicios provenientes del exterior, entre otras modalidades.

En cuanto a los países donde la industria del cine está fuertemente desarrollada, se encuentra, en primer lugar, Estados Unidos de América, que si bien no es el que mayor número de películas produce, es el que más recaudación y asistencia del consumidor tiene en todo el mundo; en segundo lugar está la India (con el mayor número de películas producidas al año); en tercer lugar, Japón (con una producción considerable de películas del género anime); y el octavo lugar (luego de Nigeria, China, Corea del Sur y Turquía) lo ocupa Irán, donde únicamente se exhiben películas nacionales por políticas de Estado, lo cual, aunque ha limitado la producción cinematográfica, ha impulsado considerablemente el consumo de taquilla iraní (Icónica, 2020).

La justificación de la investigación se debe a que resulta importante observar los resultados que dan las correlaciones de las variables de las hipótesis para concluir si es recomendable una propuesta de exoneración al IGV e IPM, así como una inafectación al IEPND, a los espectáculos cinematográficos de producción nacional como política fiscal de Estado para, de esa forma, incentivar la asistencia al cine para el consumo de películas peruanas. Mientras que la principal limitación del estudio fue la falta de antecedentes directamente relacionados con las variables de las hipótesis planteadas, por lo que, si bien es una limitante, esto hace innovador al estudio y un potencial antecedente para futuras investigaciones.

\section{MATERIAL Y MÉTODOS}

Esta investigación tiene un enfoque cuantitativo, de tipo correlacional, transversal y descriptivo. El diseño es no experimental. La unidad de análisis son los consumidores de espectáculos de cine, siendo su población de estudio los asistentes a las salas de Cineplanet, sede Centro Cívico del distrito del Cercado de Lima, que en alguna oportunidad asistieron durante el periodo 2017-2019.

Teniendo en cuenta que la población es infinita; es decir, no se puede determinar el número exacto de asistentes a las salas de cine en dicha sede, se obtuvo el tamaño de la muestra luego de aplicar la siguiente operación probabilística:

$$
\mathrm{n}=\frac{Z^{2} x p \times q}{d^{2}}
$$

En la cual " $n$ " fue el tamaño para la muestra; " $Z$ " fue su nivel de confianza, el cual es de 95\%, dando 1,96; "p" es la probabilidad de éxito que es igual a 0,50 ; "q" es la probabilidad de fracaso que es igual a 0,50; y "d" es el nivel de error que es igual a 0,05 .

$$
384,16=\frac{(1,96)^{2} \times 0,5 \times 0,5}{(0,05)^{2}}
$$

Luego de aplicada la fórmula al tamaño de la muestra, se obtiene que la selección será de 384 consumidores que asistieron a los espectáculos cinematográficos en las salas de Cineplanet sede Centro Cívico del distrito del Cercado de Lima durante el periodo 2017-2019. El rango de edad de dichos consumidores fue de entre los 15 a 53 años. A estos se les realizó una encuesta virtual con 18 ítems utilizando la escala de Likert. Los datos para los resultados y estadísticas se procesaron con el software SPSS en su versión 22.

\section{RESULTADOS}

Para la prueba de la hipótesis general, de los resultados de la Tabla 1, teniendo en cuenta que "regular" es igual a indicar la no tributación al consumo de espectáculos cinematográficos, se observa que 22 personas $(5,73 \%)$ del total de encuestados respondió que, en caso no hubiese tributación al consumo de espectáculos cinematográficos, la asistencia del consumidor al cine por filmes peruanos sería baja. Por otro lado, 68 personas $(17,71 \%)$ indican que la asistencia del consumidor al cine por filmes peruanos sería regular. Otras 181 personas $(47,14 \%)$ de la referida encuesta indican que la asistencia del consumidor al cine por filmes peruanos sería alta, y otras 22 personas (5,73\%), que sería muy alta.

Se observa que 23 personas (6\%) del total de encuestados que respondió al supuesto de que la tributación al consumo de espectáculos cinematográficos fuese "alta" indican que la asistencia del consumidor al cine por filmes peruanos sería regular y otras 22 personas $(5,73 \%)$ indican que sería alta. 
Por último, se observa que 23 personas (6\%) del total de encuestados que respondió que la tributación al consumo de espectáculos cinematográficos fuese "muy alta" indican que la asistencia del consumidor al cine por filmes peruanos sería baja, y otras 23 (6\%) indican que sería alta.

Interpretando estos resultados, en caso no existiese tributación al consumo sobre los espectáculos cinematográficos por filmes peruanos, un total de 203 personas, eso es 181 personas $(47,14 \%)$ en asistencia alta y 22 personas $(5,73 \%)$ en asistencia muy alta, consideran al precio como factor relevante para asistir al cine. No obstante, para 91 personas $(23,69 \%)$ no existe correlación entre las variables. Por otro lado, unas 22 personas $(5,73 \%)$ manifestaron que si la tributación fuese alta, la asistencia sería igualmente alta, y otras 23 personas (6\%) manifestaron que si la tributación fuese muy alta, la asistencia sería alta; por lo que, estas personas valoran otros factores distintos al precio al elegir ver filmes peruanos, lo cual demostraría que, aún con la tributación al consumo sobre estos filmes, sí asistirían (Ver Figura 1).

Para contrastar la hipótesis general, se usó el criterio de valor $\mathrm{p}=0,05$. Si en la prueba de la hipótesis se obtiene un

Tabla 1

Correlación entre la tributación al consumo de espectáculos cinematográficos y la asistencia del consumidor al cine por filmes peruanos 2017-2019

La asistencia del consumidor al cine por filmes peruanos 2017-2019

\begin{tabular}{|c|c|c|c|c|c|c|c|}
\hline & & & Bajo & Regular & Alta & Muy alta & Total \\
\hline \multirow{8}{*}{$\begin{array}{l}\text { La tributación al consumo } \\
\text { de espectáculos } \\
\text { cinematográficos }\end{array}$} & \multirow{2}{*}{$\begin{array}{l}\text { Regular } \\
\text { (cero) }\end{array}$} & Recuento & 22 & 68 & 181 & 22 & 293 \\
\hline & & $\%$ del total & $5,7 \%$ & $17,7 \%$ & $47,1 \%$ & $5,7 \%$ & $76,3 \%$ \\
\hline & \multirow{2}{*}{ Alta } & Recuento & 0 & 23 & 22 & 0 & 45 \\
\hline & & $\%$ del total & $0,0 \%$ & $6,0 \%$ & $5,7 \%$ & $0,0 \%$ & $11,7 \%$ \\
\hline & \multirow{2}{*}{ Muy alta } & Recuento & 23 & 0 & 23 & 0 & 46 \\
\hline & & $\%$ del total & $6,0 \%$ & $0,0 \%$ & $6,0 \%$ & $0,0 \%$ & $12,0 \%$ \\
\hline & \multirow{2}{*}{ Total } & Recuento & 45 & 91 & 226 & 22 & 384 \\
\hline & & $\%$ del total & $11,7 \%$ & $23,7 \%$ & $58,9 \%$ & $5,7 \%$ & $100,0 \%$ \\
\hline
\end{tabular}

Fuente: Elaboración propia

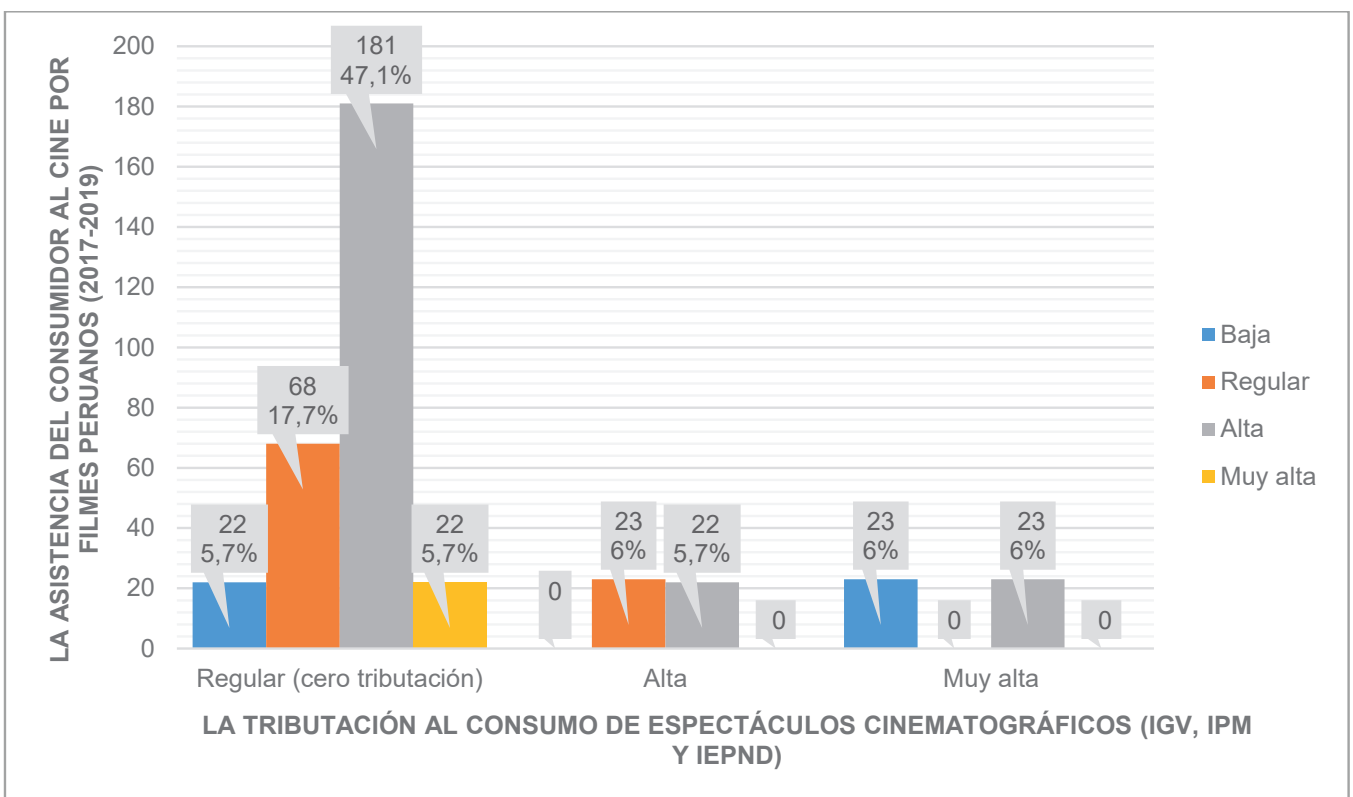

Figura 1. Correlación entre la tributación al consumo de espectáculos cinematográficos y la asistencia del consumidor al cine por filmes peruanos 2017-2019

Fuente: Elaboración propia 
valor de "p" mayor o igual (>=) a 0,05, entonces se aceptaría la hipótesis nula (H0). De lo contrario, si de la prueba de la hipótesis se obtiene que el valor de "p" es menor $(<)$ a 0,05 , entonces se aceptaría la hipótesis general (HA).

Aplicando la prueba Rho de Spearman, según el resultado de la Tabla 2, se tiene que, al ser el valor de "p" menor $(<)$ a $0,05 \%(<0,05)$, es decir 0,00 , se descarta la $\mathrm{H} 0$ y por tanto se acepta la HA. Así también, al ser un coeficiente de $r=-0,238$, el rango de valoración, según la Tabla 3 , es de una correlación negativa o inversa baja. En ese sentido, se determina que existe una correlación significativa inversa baja entre la tributación al consumo de espectáculos cinematográficos y la asistencia del consumidor al cine por filmes peruanos 2017-2019.

Las pruebas de las hipótesis específicas pasaron por los mismos indicadores de la hipótesis general para la medición, pues tanto el IGV, IPM e IEPND representan el mismo universo de la tributación al consumo aplicable a los espectáculos cinematográficos. En ese sentido, de la prueba de la primera hipótesis específica (HE1) se tiene que, al ser el valor de "p" menor $(<)$ a $0,05 \%(<0,05)$, es decir 0,00 , se descarta la H0 y por tanto se acepta la HE1. Así también, al ser un coeficiente de $\mathrm{r}=-0,238$, el rango de valoración, según la Tabla 3, es de una correlación negativa o inversa baja. En ese sentido, se determina que existe una correlación significativa inversa baja entre el IGV e IPM de espectáculos cinematográficos y la asistencia del consumidor al cine por filmes peruanos 2017-2019.

Igualmente, de la prueba de la segunda hipótesis específica (HE2) se tiene que, al ser el valor de "p" menor $(<)$ a $0,05 \%$ $(<0,05)$, es decir 0,00 , se descarta la $\mathrm{H} 0$ y por tanto se acepta la HE2. Así también, al ser un coeficiente de $\mathrm{r}=-0,238$, el rango de valoración, según la Tabla 3 , es de una correlación negativa o inversa baja. En ese sentido, se determina que existe una correlación significativa inversa baja entre el IEPND de espectáculos cinematográficos y la asistencia del consumidor al cine por filmes peruanos 2017-2019.

Tabla 2

Prueba Rho de Spearman para correlación en hipótesis general

\begin{tabular}{|c|c|c|c|c|}
\hline \multicolumn{5}{|c|}{ Correlaciones } \\
\hline & & & $\begin{array}{c}\text { La tributación al consumo } \\
\text { de espectáculos cinema- } \\
\text { tográficos }\end{array}$ & $\begin{array}{l}\text { La asistencia del consu- } \\
\text { midor al cine por filmes } \\
\text { peruanos } 2017-2019\end{array}$ \\
\hline \multirow{6}{*}{$\begin{array}{l}\text { Rho de } \\
\text { Spearman }\end{array}$} & \multirow{3}{*}{$\begin{array}{l}\text { La tributación al consumo } \\
\text { de espectáculos cinemato- } \\
\text { gráficos }\end{array}$} & Coeficiente de correlación & 1,000 & $-0,238^{* *}$ \\
\hline & & Sig. (bilateral) & . & 0,000 \\
\hline & & $\mathrm{N}$ & 384 & 384 \\
\hline & \multirow{3}{*}{$\begin{array}{l}\text { La asistencia del consumi- } \\
\text { dor al cine por filmes pe- } \\
\text { ruanos } 2017-2019\end{array}$} & Coeficiente de correlación & $-0,238^{* *}$ & 1,000 \\
\hline & & Sig. (bilateral) & 0,000 & . \\
\hline & & $\mathrm{N}$ & 384 & 384 \\
\hline
\end{tabular}

**. La correlación es significativa en el nivel 0,01 (2 colas).

Fuente: Elaboración propia

Tabla 3

Tabla de valoración de rangos de prueba de hipótesis

\begin{tabular}{|c|c|c|c|}
\hline Rango & Valoración & Rango & Valoración \\
\hline 1 & Correlación positiva o directa perfecta & 0 & Correlación nula \\
\hline 0,9 a 0,99 & Correlación positiva o directa muy alta & $-0,01$ a $-0,19$ & Correlación negativa o inversa muy baja \\
\hline 0,7 a 0,89 & Correlación positiva o directa alta & $-0,2$ a $-0,39$ & Correlación negativa o inversa baja \\
\hline 0,4 a 0,69 & Correlación positiva o directa moderada & $-0,4$ a $-0,69$ & Correlación negativa o inversa moderada \\
\hline 0,2 a 0,39 & Correlación positiva o directa baja & $-0,7$ a $-0,89$ & Correlación negativa o inversa alta \\
\hline 0,01 a 0,19 & Correlación positiva o directa muy baja & $-0,9$ a $-0,99$ & Correlación negativa o inversa muy alta \\
\hline 0 & Correlación nula & -1 & Correlación negativa o inversa perfecta \\
\hline
\end{tabular}

Fuente: Elaboración propia 


\section{DISCUSIÓN}

Comparando con la postura de Alfaro (2017) y sus resultados positivos de la exoneración al IGV del sector construcción en la región de San Martín, se observa que no converge íntegramente con los resultados de la presente investigación, pues la exoneración o inafectación de los tributos al consumo de espectáculos cinematográficos no tiene una correlación inversa perfecta con la asistencia del consumidor al cine por filmes peruanos según el periodo 2017-2019; es decir, no se puede afirmar que a menor tributo al consumo de esta actividad de origen nacional mayor asistencia del consumidor al cine por filmes peruanos.

No obstante, dado que las variables de esta investigación no tienen una correlación nula, sino una correlación inversa baja, podría darse la inafectación al IEPND a la actividad cinematográfica de origen nacional; pues, según los resultados de Chang (2020), los tributos municipales como el IEPND no representan un ingreso fiscal significativo para las municipalidades, por lo que, una inafectación al IEPND no representaría un costo fiscal importante, quedando pendiente hacer una investigación sobre la inafectación o exoneración al IGV e IPM frente al costo fiscal del Gobierno central por este beneficio al contribuyente.

Ahora, comparando con la postura de Gil (2015), quien manifiesta que en España el precio es un elemento determinante para el consumidor al momento de asistir a una sala de cine, puede sostenerse que la correlación inversa baja obtenida en esta investigación admita que una exoneración o inafectación de los tributos al consumo de espectáculos cinematográficos de películas peruanas, pueda dar como resultado el aumento de la asistencia del consumidor al cine por filmes peruanos por sobre las extranjeras, aun cuando no sea determinante.

Tanto la postura de Gil (2015) como los resultados de esta investigación confirman que el precio de los boletos de entrada incide en la decisión del consumidor de asistir o no al cine, pues se demuestra que un precio menor, producto de las inafectaciones o exoneraciones a la tributación al consumo de espectáculos cinematográficos nacionales, podría beneficiar esta actividad al aumentar la asistencia del espectador a los cines para ver películas peruanas.

Dicho esto y, sobre la base de los resultados, se concluye que existe una relación significativa inversa baja entre la tributación al consumo de espectáculos cinematográficos, específicamente por IGV, IPM e IEPND, y la asistencia del consumidor al cine por filmes peruanos 2017-2019. El aumento del valor del precio de venta del boleto de entrada al cine generada por dichos impuestos no es determinante al momento de elegir ver una película peruana o extranjera por parte de los espectadores; no obstante, es un factor, entre otros, que incide en la decisión, por lo que establecer una exoneración o inafectación de dichos tributos al consumo a los espectáculos cinematográficos peruanos en los cines podría generar un aumento de la asistencia del consumidor al cine por filmes peruanos.

Si bien no hay una correlación inversa perfecta de variables, a partir de los resultados, se puede observar que los incentivos tributarios, en cuanto a los tributos al consumo, podrían funcionar en los servicios de espectáculos cinematográficos nacionales. Los otros factores dependerán de la calidad cinematográfica de la película, el nivel de publicidad en su estreno y las premiaciones que reciba $\mathrm{e}$ incidan en el interés del potencial espectador, quien también influirá al momento de decidir entre consumir una película peruana o extranjera.

Como conclusiones de esta investigación, al no poder utilizarse el crédito fiscal de lo que es destinado a operaciones exoneradas o inafectas al IGV e IPM, aun con un incentivo tributario a los espectáculos cinematográficos nacionales en los cines, los precios de los boletos de las entradas no disminuirían en cuanto a estos dos impuestos, pues el empresario al no poder aplicar crédito fiscal de sus compras recuperaría dicha pérdida manteniendo el mismo precio en sus boletos. Por lo tanto, la recomendación sería aplicar una excepción a la regla del requisito sustancial del crédito fiscal o aplicar un crédito a favor equivalente; esto bajo determinadas condiciones para el empresario que demuestre disminución, por el valor del IGV e IPM, al precio del boleto de entrada.

Queda como agenda para futuras investigaciones el determinar el costo tributario que devendría al fisco una exoneración o inafectación del IGV, IPM e IEPND a esta actividad nacional, es decir: ¿Cuál sería la relación entre la exoneración o inafectación del IGV, IPM e IEPND a los espectáculos cinematográficos peruanos y el costo tributario al fisco por dichos beneficios tributarios? Así como realizar más investigaciones de tipo explicativas sobre la tributación al consumo de esta actividad y su influencia en la asistencia a los cines por filmes nacionales, debido a que esta investigación no ha encontrado antecedentes directamente vinculados con sus variables, a través de la pregunta: ¿De qué manera la tributación al consumo de espectáculos cinematográficos incide en la asistencia a los cines por filmes nacionales? Otra futura investigación sería determinar si con un impuesto extraordinario a los espectáculos cinematográficos de películas extranjeras daría como resultado el aumento de la asistencia del consumidor al cine por filmes peruanos, es decir: ¿De qué manera un impuesto extraordinario a los espectáculos cinematográficos de películas extranjeras incide en la asistencia del consumidor al cine por filmes peruanos? 


\section{REFERENCIAS}

Alfaro, W. (2017). La exoneración del IGV y su incidencia en el desarrollo comercial de las empresas constructoras de la región San Martín año 2015 (Tesis para optar el grado académico de maestro en Tributación). Recuperada de http://hdl.handle.net/20.500.12952/3823

Chang, M. (2020). Sistema tributario municipal: un análisis de su obsolescencia sobre la recaudación tributaria en los gobiernos locales; caso de la municipalidad distrital de Cayma, provincia y departamento de Arequipa, 2015-2018 (Tesis para optar el grado académico de magíster en Ciencia Política y Gobierno con mención en Políticas Públicas y Gestión Pública). Recuperada de http://hdl.handle.net/20.500.12404/16626

Decreto de Urgencia No 022-2019, Decreto de Urgencia que promueve la Actividad Cinematográfica y Audiovisual. (2019). Poder Ejecutivo. Diario Oficial El Peruano, 08 de diciembre.

Decreto Supremo No 055-99-EF, Texto Único Ordenado de la Ley del Impuesto General a las Ventas e Impuesto Selectivo al Consumo. (1999). Poder Ejecutivo. Diario Oficial El Peruano, 14 de abril.

Decreto Supremo No 156-2004-EF, Texto Único Ordenado de la Ley de Tributación Municipal. (2004). Poder Ejecutivo. Diario Oficial El Peruano, 11 de noviembre.

Decreto Ley No 19327, Ley de Fomento de la Industria Cinematográfica. (1972). Poder Ejecutivo. Diario Oficial El Peruano, 28 de marzo.

Dirección del Audiovisual, la Fonografía y los Nuevos Medios. (2020). Memorando No 000140-2020-DAFO/MC. Lima: Oficina de Atención al Ciudadano y Gestión Documentaria.

El Comercio. (04 de agosto de 2019). El 49\% de peruanos afirma ir al cine al menos una vez a la semana. Recuperado de https://elcomercio.pe/

Gestión. (16 de enero de 2020). Conozca el comportamiento del consumo de cine de los peruanos. Recuperado de https://gestion.pe/
Gil, M. (2015). Comportamiento del consumidor de cine en salas: factores motivacionales y tipología del consumidor (Tesis doctoral en el Departamento de Comercialización e Investigación de Mercados, Universidad Complutense de Madrid, España). Recuperada de https://eprints.ucm.es/id/eprint/46080/

Huanqui, S. (2017). Impacto económico del sector cinematográfico y audiovisual y análisis costo-beneficio de la implementación del anteproyecto de la Ley de la Cinematografía y el Audiovisual. Recuperado de http:// dafo.cultura.pe/wp-content/uploads/2017/09/Estudio-UP-Ley-de-Cine-VF.pdf

Icónica. (04 de junio de 2020). Las principales industrias fílmicas del mundo. Recuperado de http://revistaiconica. com/las-principales-industrias-filmicas-del-mundo/

Ley $\mathrm{N}^{\circ}$ 13936, Liberando de toda clase de impuestos y arbitrios, la exhibición de las películas nacionales, de largo metraje, producidas en el país por empresas nacionales. (1962). Congreso de la República del Perú, Diario Oficial El Peruano, 27 de enero.

Ley $\mathrm{N}^{\circ}$ 26370, Ley de la Cinematografía Peruana. (1994). Congreso de la República del Perú. Diario Oficial El Peruano, 18 de octubre.

RPP Noticias. (22 de julio de 2020). "Retablo", laureada cinta peruana, ingresa al catálogo de Netflix este 29 de julio. Recuperado de https://rpp.pe/tv/netflix/netflix-retablo-cinta-dirigida-por-alvaro-delgado-aparicio-ingresa-al-catalogo-de-la-plataforma-de-strea$\underline{\text { ming-noticia }-1281755 \text { ? } r e f=r p p}$

Ruiz de Castilla, F. (19 de abril de 2008). Impuesto a los espectáculos públicos no deportivos [mensaje en blog]. Recuperado de http://blog.pucp.edu.pe/blog/franciscoruiz/2008/04/19/impuesto-a-los-espectaculos-publicos-no-deportivos/ 